Clinical

\title{
Social determinants of health: does socioeconomic status affect access to staging imaging for men with prostate cancer
}

\author{
Brian D. Kelly $y^{1,2}$, Marlon Perera $\mathbb{D}^{1,3^{凶}}$, Damien M. Bolton $\mathbb{D}^{1}$ and Nathan Papa ${ }^{1,4}$ \\ (c) The Author(s) 2022
}

Socioeconomic status (SES), race and geographical factors are known to impact prostate cancer management and outcomes. We aimed to assess these factors with regard to access to novel imaging in prostate cancer. Using the Prostate Cancer Outcomes Registry of Victoria (PCOR-Vic) we identified 5256 men diagnosed with prostate cancer via biopsy. Following the introduction of government rebate, the access to MRI improved with respect to SES. Access to PET imaging remains poor with respect to SES and geographical location in the absence of Federal funding. Further improvements for men with low SES and regional areas to access PET staging.

Prostate Cancer and Prostatic Diseases; https://doi.org/10.1038/s41391-022-00508-7

Social determinants of health $(\mathrm{SDOH})$ include socioeconomic status (SES), race and geographical access to healthcare. Low SES is associated with a higher incidence of higher-grade prostate cancer at diagnosis and increased mortality, the cause of which is multifactorial and complex [1-4]. However, it is likely that access to key diagnostic modalities are implicated. In prostate cancer, significant advances to radiologic staging have occurred following the introduction of multiparametric magnetic resonance imaging (MRI) [5] and positron emission tomography (PET) [6, 7]. We aimed to assess the impact of $\mathrm{SDOH}$ on access to novel imaging modalities in prostate cancer.

It is pertinent to note that to improve prostate cancer management in men in Australia, mpMRI of the prostate for patients suspected of having prostate cancer has been subsidised by the Australian government in July 2018. This has enabled greater access for the general public via the public healthcare system, as patients meeting the Medicare Benefits Scheme (MBS) criteria can undergo mpMRI with no out-of-pocket fee [8]. Once a service is added to the Medicare benefit schedule, all men have access to the rebated service, regardless of income or SES status. At present, with current applications pending, PET imaging has not received similar federal subsidisation.

We performed a review of the Prostate Cancer Outcomes Registry of Victoria (PCOR-Vic) in July 2020 assessing the SDOH of men newly diagnosed with prostate cancer from January 2017 to December 2018 [9]. The registry does not collect ethnicity but does record Australian Aboriginal or Torres Strait Islander status. These men comprised $<0.2 \%$ of the cohort, the small numbers precluded meaningful analysis. Using Australian Bureau of Statistics correspondences and linked geocoded data from the Victorian Cancer Registry, we assigned each deidentified patient a percentile rank of SES and determined their major metropolitan or regional residence status. The measure of SES used in this study is the Index of Relative Socioeconomic Advantage and Disadvantage (IRSAD) published by the Australian Bureau of Statistics [10]. This measure incorporates numerous variables but the strongest indicators of low SES are an annual household income in the lowest two deciles $(<A \$ 26,000)$ and non-completion of the final year of high school. Locally weighted, running mean smoothing plots were generated to illustrate changes over time for the SDOH metrics in men receiving specific imaging compared to the whole sample population. For $C T$, bone scan and PET regressions, only men with grade group 2 and PSA $>10 \mathrm{ng} / \mathrm{ml}$ or grade group 3+ were analysed.

During this timeframe there were 5256 men diagnosed via prostate biopsy. Patient demographics and characteristics are summarized in Supplementary Table 1. Prior to the MBS reimbursement, the mean percentile difference in SES between patients receiving MRI or not was 5.7 (95\% Cl: 3.5-7.0) favouring more advantaged men. After July 2018, the difference was 3.5 (95\% Cl: 0.5-6.5). The running mean difference showed a narrowing of the SES access gap beginning prior to the MBS change (Fig. 1A). The SES gap for PET imaging was maintained over the 2 years at an average of 9.0 (95\% Cl: 6.2-1.7). No large percentage difference, $1.6(95 \% \mathrm{Cl}$ : $-1.1-4.4)$, was observed favouring metropolitan vs regional residence for access to MRI. For PET, the corresponding difference was 8.1 (95\% Cl: 4.5-11.6) with the regional access gap not appearing to decrease (Fig. 1B).

\footnotetext{
${ }^{1}$ Department of Urology, Austin Health, Heidelberg, Melbourne, VIC, Australia. ${ }^{2}$ Department of Surgical Oncology, Peter MacCallum Cancer Centre, Melbourne, VIC, Australia. ${ }^{3}$ Department of Urology, Memorial Sloan Kettering Cancer Center, NYC, NY, USA. ${ }^{4}$ School of Public Health and Preventive Medicine, Monash University, Melbourne, VIC, Australia. 凶email: marlonlperera@gmail.com
} 


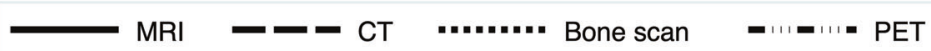

A

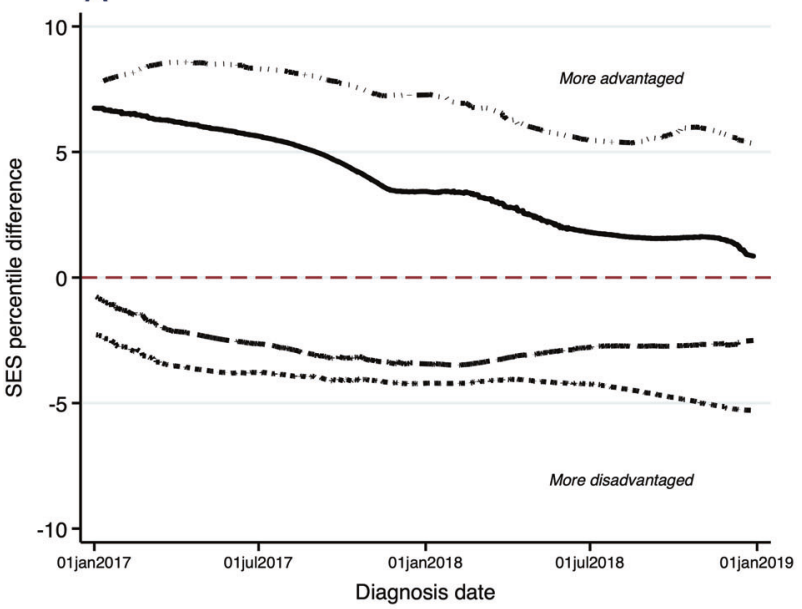

B

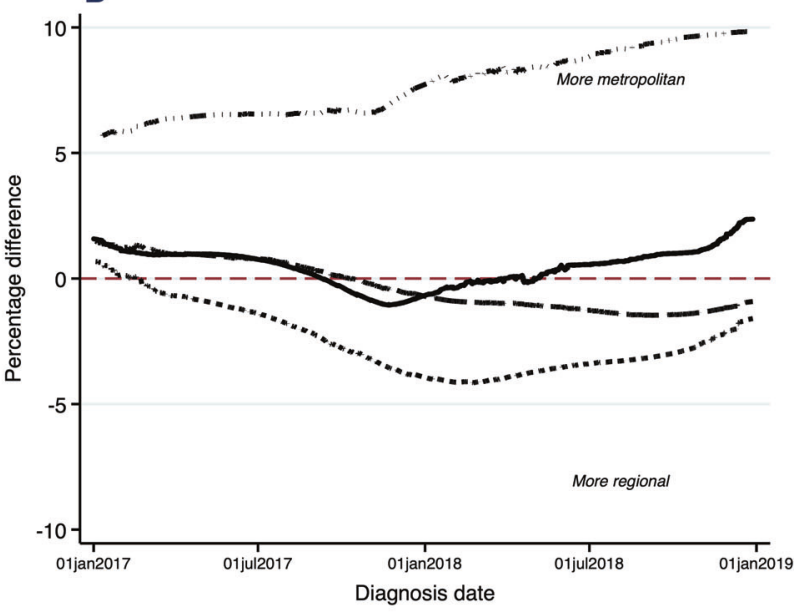

CT, Bone Scan, PET only for grade group 2 with PSA $\geq 10 \mathrm{ng} / \mathrm{ml}$ OR grade group 3+

Fig. 1 Locally weighted smoothed running mean differences between patients receiving the imaging modality and the total sample. A Difference in SES percentile. B Percentage difference between residence in major city and regional areas.

Our results suggest limited access to PET for prostate cancer in patients with lower SES. Conversely, access to MRI in patients with lower SES improved along with the introduction of federally subsidised MRI scans via the Medicare Benefits Scheme. It is likely that PET uptake is following a similar uptake pattern to that of MRI prior to subsidisation, implying that men with lower SES have reduced access to PET imaging due to significant out-of-pocket expenses. A subsequent analysis following the likely upcoming listing of PET imaging on the MBS will be of interest.

The current analysis highlights the compromised access to novel imaging modalities in patients who live outside of a major city. There is similar access to MRI, CT and bone scans for most men irrespective of their geographic location. However, over time, regional access to PET imaging has not improved. This perhaps is a reflection of the fact that most small regional medical centers do perform $C T, M R I$ and bone scans whereas PET imaging is predominantly only available at large public and private institutions within metropolitan Melbourne. Further, men with low SES and living in regional Victoria are perhaps unwilling to travel to a large academic institution in the metropolitan city of Melbourne to access a PET scan or to enrol in a clinical trial assessing the use of various PET imaging.

Given the improvements in access to MRI for men of a low SES, which improves cancer detection of clinically significant cancer, there needs to be further improvements for men with low SES to access superior PET staging, and in particular for low SES men from regional areas.

\section{REFERENCES}

1. Major JM, Norman Oliver M, Doubeni CA, Hollenbeck AR, Graubard BI, Sinha R. Socioeconomic status, healthcare density, and risk of prostate cancer among African American and Caucasian men in a large prospective study. Cancer Causes Control. 2012;23:1185-91.

2. Du XL, Fang S, Coker AL, Sanderson M, Aragaki C, Cormier JN, et al. Racial disparity and socioeconomic status in association with survival in older men with local/regional stage prostate carcinoma: findings from a large community-based cohort. Cancer. 2006;106:1276-85.

3. Dean LT, Gehlert S, Neuhouser ML, Oh A, Zanetti K, Goodman M, et al. Social factors matter in cancer risk and survivorship. Cancer Causes Control. 2018;29:611-8.
4. Coughlin SS. A review of social determinants of prostate cancer risk, stage, and survival. Prostate Int. 2020;8:49-54.

5. Ahmed HU, El-Shater Bosaily A, Brown LC, Gabe R, Kaplan R, Parmar MK, et al. Diagnostic accuracy of multi-parametric MRI and TRUS biopsy in prostate cancer (PROMIS): a paired validating confirmatory study. Lancet. 2017;389:815-22.

6. Perera M, Papa N, Roberts M, Williams M, Udovicich C, Vela I, et al. Gallium-68 Prostate-specific Membrane Antigen Positron Emission Tomography in Advanced Prostate Cancer-Updated Diagnostic Utility, Sensitivity, Specificity, and Distribution of Prostate-specific Membrane Antigen-avid Lesions: A Systematic Review and Meta-analysis. Eur Urol. 2020;77:403-17.

7. Papa N, Perera M, Murphy DG, Lawrentschuk N, Evans M, Millar JL, et al. Patterns of primary staging for newly diagnosed prostate cancer in the era of prostate specific membrane antigen positron emission tomography: A population-based analysis. J Med Imaging Radiat Oncol. 2021;65:649-54. https://doi.org/10.1111/ 1754-9485.13162.

8. New Medicare Benefits Schedule (MBS) Items for multiparametric magnetic resonance imaging (mpMRI) of the prostate. In: Health AGDo (ed): http://www. mbsonline.gov.au/internet/mbsonline/publishing.nsf/Content/FactsheetMRIProstate, 2018.

9. Evans SM, Millar JL, Wood JM, Davis ID, Bolton D, Giles GG, et al. The Prostate Cancer Registry: monitoring patterns and quality of care for men diagnosed with prostate cancer. BJU Int. 2013;111:E158-166.

10. 2033.0.55.001 - Census of Population and Housing: Socio-Economic Indexes for Areas (SEIFA), Australia, 2016. In: Statistics ABo (ed). Department of Health Services: https:// www.abs.gov.au/ausstats/abs@.nsf/Lookup/by\%20Subject/2033.0.55.001 2016 Main \%20Features IRSAD 20, 2018.

\section{AUTHOR CONTRIBUTIONS}

BK: manuscript draft. MP: manuscript draft, manuscript revision. DB: supervision, manuscript revision. NP: data collection, data analysis.

\section{FUNDING}

Open Access funding enabled and organized by CAUL and its Member Institutions.

\section{COMPETING INTERESTS}

MP is sponsored by the Australian-America Fulbright Commission administered through a 2021-2022 Fulbright Future Scholarship funded by The Kinghorn Foundation. 
ETHICAL APPROVAL

The following research was approved by Institutional ethical board (HREC/16/Alfred/98).

\section{ADDITIONAL INFORMATION}

Supplementary information The online version contains supplementary material available at https://doi.org/10.1038/s41391-022-00508-7.

Correspondence and requests for materials should be addressed to Marlon Perera.

Reprints and permission information is available at http://www.nature.com/reprints

Publisher's note Springer Nature remains neutral with regard to jurisdictional claims in published maps and institutional affiliations.
Open Access This article is licensed under a Creative Commons Attribution 4.0 International License, which permits use, sharing, adaptation, distribution and reproduction in any medium or format, as long as you give appropriate credit to the original author(s) and the source, provide a link to the Creative Commons license, and indicate if changes were made. The images or other third party material in this article are included in the article's Creative Commons license, unless indicated otherwise in a credit line to the material. If material is not included in the article's Creative Commons license and your intended use is not permitted by statutory regulation or exceeds the permitted use, you will need to obtain permission directly from the copyright holder. To view a copy of this license, visit http://creativecommons. org/licenses/by/4.0/.

(c) The Author(s) 2022 